\title{
Formação de educadores populares a partir de parceria entre universidade e movimento popular
}

Training of popular educators based on a partnership between the university and the popular movement

Maria Clarisse vieira ${ }^{1}$

Luciana de Oliveira Pinto

\section{Resumo}

Este artigo discute características do processo de formação e perfil dos educadores que participaram de formação voltada para professores que atuam no Programa DF Alfabetizado nas Regiões Administrativas do Paranoá e Itapoã (DF), ocorrida em 2016, fruto de parceria entre o Centro de Cultura e Desenvolvimento do Paranoá e Itapoã (Cedep), oriundo do movimento popular dessas comunidades, Universidade de Brasília (UnB) e Coordenação Regional de Ensino (CRE). A discussão ampara-se nos pressupostos teóricos do materialismo histórico-dialético de Marx e Engels, na abordagem histórico-cultural de Bakhtin e Vigotski, na pedagogia libertadora de Freire e na proposta pedagógica de análise e superação de situações-problemasdesafio, construção de textos coletivos, fórum e acolhimento amoroso dos alfabetizandos. Os educadores avaliaram de forma positiva o processo de formação inicial e ressaltaram a importância das oficinas vivenciadas, o compromisso em adotá-las em suas turmas de alfabetização, haja vista a troca de experiência, a discussão dos problemas enfrentados ao longo da

\footnotetext{
1 Professora da Faculdade de Educação e do Programa de pós-graduação em Educação da UNB. Doutora em Educação pela UFMG e mestre em educação pela UFU. Coordenadora do Genpex- UnB - Grupo de ensino pesquisa e extensão em educação popular e estudos filosóficos e histórico culturais. E-mail: mclarissev@yahoo.com.br.

${ }^{2}$ Mestrado em Educação (2017) e Economia (1993) pela Universidade de Brasília, Graduação em pedagogia pela Universidade Paulista (2015), Graduação em Ciências Econômicas pela Universidade de Brasília (1988), Graduação em Comunicação Social - Jornaismo pela Universidade Federal da Bahia (1983) e Especialização em Processos de Alfabetização na Vida Adulta pela Universidade de Brasília (2005). Educadora do Programa BB Educar desde 2004 pela Fundação Banco do Brasil. E-mail: luciana200000@terra.com.br.
} 
prática educativa e o desenvolvimento conjunto de propostas visando a sua superação.

Palavras-chave: Formação de educadores populares. Movimento popular. Alfabetização de jovens e adultos.

\section{Abstract}

This article discusses characteristics of the formation process and profile of the educators who participated in training aimed at teachers who work in the DF Alphabetization Program, in the Administrative Regions of Paranoá and Itapoã (DF), held in 2016, as a result of a partnership between the Culture and Development Center of Paranoá and Itapoã (Cedep), coming from the popular movement of these communities, University of Brasilia (UnB) and Regional Coordination of Education (CRE). The discussion is based on the theoretical assumptions of Marx and Engels historical-dialectical materialism, on the historical-cultural approach of Bakhtin and Vigotski, on Freire's libertation pedagogy and on the pedagogical proposal of analysis and overcoming situations-problems-challenge construction of collective texts, forum and loving reception of the alphabetizing students. Educators positively assessed the initial training process, emphasized the importance of the workshops and the commitment to adopt them in their alphabetization classes there is sight the exchange of experience among educators, a joint discussion of the problems faced throughout the educational practice and the development of pedagogical alternatives for their overcoming.

Keywords: Formation of popular educators. Popular movement. Alphabetization for youth and adults.

\section{INTRODUÇÃO}

O presente artigo investiga o processo de formação de educadores populares que atuaram no âmbito do DF Alfabetizado na região do Paranoá e Itapoã (DF), por meio da experiência do $4^{\circ}$ Curso de Formação Inicial de 
Educadores, realizado em 2016, fruto de parceria entre o Centro de Cultura e Desenvolvimento do Paranoá e Itapoã (Cedep), a Universidade de Brasília (UnB) e a Coordenação Regional de Ensino (CRE) do Paranoá e Itapoã. O Programa DF alfabetizado, implementado em 2011 no DF, é a versão candanga do Programa Brasil Alfabetizado, criado em 2003, durante a primeira gestão do governo Lula.

Em função da realização do referido Programa, houve a necessidade de cada região administrativa do DF articular o processo formativo dos educadores selecionados. O artigo em tela, além de discutir características do processo de formação e perfil dos educadores participantes, analisa os fundamentos desta proposta formativa, calcada numa práxis dialética desenvolvida conjuntamente por professores e alunos da Universidade de Brasília (UnB) que fazem parte do Grupo de Ensino-Pesquisa-Extensão em Educação Popular e Estudos Filosóficos e Histórico-Culturais (Genpex).

Metodologicamente, a pesquisa é do tipo participante, com a análise qualitativa das observações e diários de campo produzidos ao longo do referido curso. Estruturalmente, o texto está dividido em cinco seções. Na primeira, apresenta-se um breve histórico do contexto de criação do Cedep e do Genpex, que ainda hoje mantém uma histórica parceria na formação de educadores populares que atuam na alfabetização de jovens e adultos. Na segunda, é discutido o Programa DF Alfabetizado e o contexto no qual Cedep e Genpex associam-se à Coordenação Regional de Ensino visando à implementação do referido Programa no Paranoá e Itapoã. Na terceira, são analisados os princípios teóricos do materialismo histórico-dialético de Marx e Engels; da abordagem histórico-cultural de Bakhtin e Vigotski; e da pedagogia libertadora de Freire, que dão suporte ao processo de formação dos alfabetizadores populares e ao trabalho de alfabetização por eles empreendido junto aos moradores do Paranoá e Itapoã, que se materializa a partir dos conceitos de amorosidade/acolhimento, situação-problemadesafio, texto coletivo e fórum, discutidos na quarta seção. $\mathrm{Na}$ seção seguinte, é efetuada uma reflexão sobre a práxis adotada na capacitação dos educadores que participaram do curso de formação realizado em 2016 e, por 
fim, na sexta e última seção, são apresentadas as considerações finais relativas ao processo de formação investigado.

\section{CEDEP E GENPEX: HISTÓRICO DA PARCERIA ESTABELECIDA}

Conforme atesta Jesus (2007), o movimento popular do Paranoá surge, de forma desarticulada, no início da década de 1960, capitaneado por trabalhadores responsáveis pela construção da barragem do Lago Paranoá que, após o término dos trabalhos, ocupam as casas e barracos existentes nos canteiros de obra. No decorrer das décadas seguintes, a área ocupada se expande com a chegada de familiares dos pioneiros e com novos migrantes, que deixam a sua cidade natal em busca de melhores condições de vida. Ao chegarem à nova capital do País, entretanto, são oprimidos pela constante ameaça de remoção.

Em decorrência, os moradores se organizam para suprir os bens e serviços indispensáveis à sua sobrevivência: água, energia elétrica, transporte, alimentação, educação, entre outros. Reis (2011) ressalta que esse processo de mobilização emergiu da ação de um grupo de jovens católicos que, no desdobramento de sua ação-reflexão-ação religiosa, se engajaram num movimento comunitário, denominado inicialmente Grupo Pró-Moradia do Paranoá que, no decorrer dos anos, se transforma no Centro de Cultura e Desenvolvimento do Paranoá (Cedep).

Nesse movimento de construção da história, constatam que a alfabetização de jovens e adultos se coloca como necessária ao fortalecimento da luta coletiva por moradia e uma vida mais digna, na medida em que a aprendizagem da leitura, da escrita e do cálculo os auxiliam na busca reflexiva por soluções para os problemas enfrentados pela comunidade.

A luta por alfabetização, portanto, não nasce isolada como iniciativa exclusivamente escolar, mas vinculada ao conjunto de lutas do Paranoá. Como a maior parte da população não era alfabetizada, o grupo vai atrás do acesso de jovens e adultos à escolarização, mas uma escolarização que não 
suprisse apenas os anseios da leitura e da escrita, mas a da formação crítica da comunidade em relação as suas necessidades. Com a extinção do MOBRAL, em 1985, e sem o apoio do Governo do Distrito Federal, busca na UnB uma alternativa de parceria, que ajude a fundamentar uma educação significativa para os jovens e adultos não alfabetizados do Paranoá. Eis que são recebidos e acolhidos pela Faculdade de Educação (FE/UnB).

Em 1986, inicia-se a parceria Paranoá-UnB. O grupo da FE/UnB levanta a necessidade de conhecer a realidade dos não-alfabetizados, e junto com o movimento popular realiza um censo populacional que reforça a necessidade de alfabetização. Enquanto isso, alguns estudantes da FE/UnB são convidados a conhecer os aspectos da alfabetização de adultos, já que os estudos relativos à formação do professor eram basicamente voltados à alfabetização de crianças.

A partir deste momento, os moradores, organizados e mobilizados em torno do Cedep, pressionam o Estado, alcançando várias melhorias, dentre as quais se destaca a edição do Decreto 11.208, de 17.08.88, que viabilizou a fixação definitiva dos moradores no Paranoá (GDF, 1988). Além disso, mantém até hoje a parceria iniciada com a UnB, que tem como mote:

\footnotetext{
Uma alfabetização onde o aprendizado da leitura, escrita, cálculos e demais linguagens é feito através da discussão e encaminhamentos de superação dos problemas enfrentados pela comunidade. (...) A partir desse momento, as pessoas passam a ter mais consciência da importância de se ter conhecimento dos direitos e saber lutar para que estes sejam respeitados (SANTOS, 2011, p.30).
}

Não obstante a fixação dos antigos moradores do Paranoá, o fluxo migratório para a região permaneceu intenso. A partir do final da década de 1990, inicia-se a ocupação, por parte desses migrantes, de lotes ociosos na região do Itapoã, que se situam numa área próxima ao Paranoá. Gradativamente a comunidade aumenta, com a chegada de familiares de antigos moradores do Paranoá, em busca de moradia própria (GDF/CODEPLAN, 2016).

O Cedep encampa a luta, organiza a população e inicia um movimento pelo direito à moradia naquela comunidade, que culmina na fixação 
definitiva da população e a criação da Região Administrativa do Itapoã, através da Lei 3.527, de 03.01.2005 (GDF, 2005). Paralelamente à mobilização dos moradores, estende o trabalho de alfabetização de jovens e adultos para o Itapoã.

Nesse contexto, alunos e professores da UnB criam, juntamente com educadores oriundos do movimento popular, o Grupo de Ensino-PesquisaExtensão em Educação Popular e Estudos Filosóficos e Histórico-Culturais (Genpex) que se organiza em torno dos seguintes objetivos:

a) Inter-relacionar dialógica e dialeticamente os interesses da UnB (ensino, pesquisa, extensão) e dos migrantes moradores do Distrito Federal (DF);

b) Contribuir com um processo educativo que simultaneamente escolarize e desenvolva a mobilização e organização das camadas populares, por maiores e melhores condições de vida;

c) Aprimorar, ampliar e consolidar as iniciativas de educação popular, iniciadas em 1986, com o movimento popular da cidade do Paranoá;

d) Desenvolver permanentemente ação-reflexão-ação, com registro, sistematização, produção e socialização de conhecimento;

e) Apoiar as iniciativas da UnB e de outras instituições públicas na área de educação popular de crianças, adolescentes, jovens, adultos e idosos (Vieira, Reis e Sobral, 2015, p. 16).

A prática do grupo é embasada teoricamente na perspectiva históricocultural, partindo da práxis para a construção de um processo educativo real, concreto e significativo para a formação de sujeitos de amor, poder e saber, nos moldes preconizados por Reis (2011). Além disso, a produção e socialização de conhecimento proposta, que se coaduna com os anseios do movimento popular do Paranoá e Itapoã têm gerado uma enorme gama de artigos, livros, dissertações de mestrado e teses de doutorado nas áreas de educação, psicologia, letras e linguística.

$\mathrm{Na}$ seção seguinte será discutido o cenário no qual Cedep e Genpex se associam à Coordenação Regional de Ensino (CRE) para implantação do DF 
Alfabetizado no Paranoá e Itapoã e assumem, conjuntamente, a responsabilidade pela formação dos alfabetizadores que atuam no referido Programa.

\section{DF ALFABETIZADO: TRÍADE GENPEX, CEDEP E CRE}

Na seção anterior, ficou patente que a alfabetização de jovens e adultos do Paranoá e Itapoã foi assumida pelo movimento popular, em parceria com a UnB, tendo em vista a omissão, por parte do Estado, do seu dever em garantir uma educação de qualidade aos moradores da comunidade, notadamente no âmbito da Educação de Jovens e Adultos (EJA).

Visando reverter a situação, uma das reivindicações prioritárias do Cedep sempre foi, desde a sua criação, a implantação de uma CRE específica para a região. A luta é, portanto, pela manutenção de uma alfabetização crítica e emancipadora que conte, entretanto, com o respaldo de políticas públicas.

Após quase uma década de pressão, a CRE foi finalmente criada em 1997, mas a sua aproximação com o movimento popular ocorreu apenas a partir de 2011, com o lançamento do Programa DF Alfabetizado, que teve como base a Resolução CD/FNDE n ${ }^{\circ} 32$ (BRASIL, 2011b), fruto da adesão, ainda que tardia, do GDF ao Programa Brasil Alfabetizado (PBA), lançado pelo Governo Lula em 2003.

A parceria, dessa forma, ampliou-se a partir da atuação conjunta do Cedep, Genpex e CRE na formação de alfabetizadores do Paranoá e Itapoã, haja vista a autonomia das Coordenações Regionais na escolha do

embasamento teórico e da metodologia a ser utilizada ao longo do processo formativo do Programa, que segue as diretrizes orientadoras do PBA (BRASIL, 2011a, p. 11) que prevê "pluralidade de concepções e referenciais teóricos, metodológicos e avaliativos na perspectiva da formação crítica e emancipadora dos sujeitos".

Até 2017, foram realizadas cinco edições do Programa, ocorridas em 2012, 2013, 2014, 2016 e 2017. Em 2015, por problemas operacionais 
relativos ao repasse de recursos para pagamento da bolsa aos alfabetizadores e transição governamental, a realização do Programa foi cancelada.

A tríplice parceria tem se mantido desde então, com suas contradições, conflitos de interesse subjacentes, erros e acertos. $O$ fato é que, por intermédio dela, movimento popular, universidade e Estado tem conseguido atender, ainda que de forma parcial, a demanda da população adulta do Paranoá e Itapoã por uma alfabetização emancipadora que requer, entretanto, contínua avaliação visando a sua melhoria.

Além disso, esse trabalho conjunto de capacitação tem motivado uma parcela de educadores populares, ou seja, educadores oriundos da própria comunidade, com saberes específicos, alguns com a formação equivalente à educação básica, a aprofundarem ainda mais a sua formação, a partir do ingresso em instituições de ensino superior com o intuito de, após a conclusão de cursos de licenciatura, retornarem na condição de professor temporário ou concursado da Secretaria de Educação para ministrarem aulas em turmas de EJA da rede regular de ensino, muitas vezes em escolas onde anteriormente estudaram ou deram aulas como alfabetizadores do Programa. O processamento desse ciclo representa, na verdade, o objetivo maior da parceria estabelecida historicamente.

Por fim, importante ressaltar que, em função da característica intrínseca do Programa de "porta de entrada" para a rede regular de ensino, torna-se imprescindivel que, ao longo do curso de formação, os educadores sejam encorajados a adotarem uma pedagogia que tenha como princípio o acolhimento amoroso dos alunos e, consequentemente, o seu dissilenciamento crítico. A leitura da palavra deve, nos moldes preconizados por Freire (1987), ser precedida da leitura de mundo dos educandos.

$\mathrm{Na}$ seção seguinte, a perspectiva teórica que norteia o processo de formação de alfabetizadores do Paranoá e Itapoã, por meio da parceria entre movimento social, universidade e CRE será aprofundada, notadamente no que tange às contribuições de Marx, Engels, Bakhtin, Vigotski e Freire. 
CONSTRUINDO UMA ALFABETIZAÇÃO EMANCIPADORA: CONTRIBUIÇÕES DE MARX, ENGELS, BAKHTIN, VIGOTSKI E FREIRE

O materialismo histórico e dialético, na visão de Marx e Engels (2009), parte do princípio de que, desde sempre, o homem age sobre a natureza, transformando-a, e ao transformá-la, é transformado, pois também faz parte da natureza que transforma. Esse ciclo, contínuo e permanente, implica, em última análise, que o mundo está sempre em permanente transformação, assim como o homem, que é o responsável direto por essa transformação, na qual assume simultaneamente o papel de sujeito e objeto. A ação do homem sobre a natureza, ou seja, sobre a realidade que o cerca e da qual é parte integrante e constitutiva, é intermediada pelo trabalho, que se realiza de forma coletiva e viabiliza-se a partir das relações sociais que suscita.

Segundo Marx (1996), na produção social da própria vida, os homens contraem relações de produção que correspondem a uma etapa determinada de desenvolvimento das suas forças produtivas materiais. A totalidade dessas relações forma a estrutura econômica da sociedade, sobre a qual se levanta uma superestrutura jurídica e política, à qual correspondem formas sociais determinadas de consciência. Assim, o modo de produção da vida material condiciona o processo em geral de vida social, político e espiritual. Não é a consciência dos homens que determina seu ser, mas, ao contrário, é o seu ser social que determina sua consciência. Essa consciência, entretanto, não é uma “consciência pura”, pois:

O "espírito" tem consigo de antemão a maldição de estar "preso" à matéria, a qual nos surge aqui na forma de camadas de ar em movimento, de sons, numa palavra, da linguagem. A linguagem é tão antiga quanto a consciência - a linguagem é a consciência real prática que existe também para outros homens e que, portanto, só assim existe também para mim. E a linguagem só nasce, como a consciência, da necessidade, da necessidade orgânica de intercâmbio com outros homens. (...) A consciência é, pois, logo desde o começo, um produto social e continuará a sê-lo enquanto existirem homens (MARX e ENGELS, 2009, p. 43-44).

Dessa forma, a linguagem tem sua origem na necessidade dos seres humanos de comunicarem-se, ou seja, na interação social visando à 
transformação da natureza através do trabalho. A função da linguagem é representar o que há na consciência dos homens e estabelecer a comunicação entre eles. Consciência e linguagem se permeiam em uma relação dialética, na qual o homem sofre influência da linguagem ao relacionar-se socialmente e, concomitantemente, a influencia quando altera a realidade concreta através das suas atitudes e ações conscientes.

Por conseguinte, a linguagem é vista como o instrumental pelo qual a realidade material e objetiva influencia a consciência e, consequentemente, a vida dos homens organizados socialmente.

Aderente ao princípio de que consciência e linguagem são produtos sociais, Bakhtin (2014) postula que a própria consciência só pode surgir e se afirmar como realidade mediante a encarnação material em signo, ou seja, os signos emergem do processo de interação entre consciências individuais.

Dessa forma, a linguagem é, antes de tudo, originária da interação entre homens reais em condições históricas concretas. A palavra, nesse contexto, perpassa todas as relações entre indivíduos, sendo tecida a partir de fios ideológicos que servem de trama a essas relações em todas as suas instâncias. A palavra existe na realidade concreta, na realidade viva da língua, na condição de mediadora e signo ideológico, e não em estado de dicionário, pois:

\footnotetext{
Em toda anunciação, por mais insignificante que seja, renova-se sem cessar essa síntese dialética viva entre o psiquismo e o ideológico, entre a vida interior e a vida exterior. Em todo ato de fala, a atividade mental subjetiva se dissolve no fato objetivo da enunciação realizada, enquanto que a palavra enunciada se subjetiva no ato da descodificação que deve, cedo ou tarde, provocar uma codificação sob a forma de réplica. Sabemos que cada palavra se apresenta como uma arena em miniatura onde se entrecruzam e lutam os valores sociais de orientação contraditória. A palavra revela-se, no momento da sua expressão, como produto da interação viva das forças sociais. É assim que o psiquismo e a ideologia se impregnam mutuamente no processo único e objetivo das relações sociais (BAKHTIN, 2014, p. $67)$.
}

Vigotski (2009) comunga com essa ideia de mediação, afirmando que a relação do homem com o mundo não se dá de forma direta, mas sim mediada por sistemas simbólicos socialmente constituídos. 
Esse conceito de mediação simbólica é um dos pilares da sua psicologia histórico-cultural e implica que o indivíduo, a partir de sua experiência com o mundo objetivo e da sua relação interpessoal concreta com os seus pares socialmente organizados, internaliza as formas culturalmente estabelecidas de funcionamento psicológico e constrói o seu sistema de signos que consistirá numa espécie de "lente" para decifração do mundo.

Essa construção é um processo contínuo e dialético, na medida em que o sistema de signos por ele internalizado é alvo de permanente significação e ressignificação subjetiva, uma vez que o homem é um agente ativo que, influenciado pela cultura na qual está inserido, modifica-se e, uma vez modificado, age em relação à cultura que o modificou, modificandoa.

Nesse contexto, a cultura não é vista por Vigotski (2009) como algo estático à qual o indivíduo se submete, mas sim como um "palco de negociações", em que os seus membros estão num constante movimento de recriação e reinterpretação subjetiva de informações, conceitos e significados. Esse movimento, entretanto, não ocorre de forma harmônica, uma vez que os interesses dos grupos sociais são muito diversos e antagônicos.

Dessa forma, a cultura é fruto da interação das forças sociais e, nesse contexto, a linguagem, e mais especificamente a palavra, é uma das protagonistas da luta de classes, refletindo e sendo, ao mesmo tempo, para todas as forças envolvidas, uma das armas deste combate. Nessa disputa está embutida a luta pelo poder, pela supremacia da fala e pela hegemonia dos seus conceitos.

Por isso é tão importante para o homem, e em especial para os oriundos das classes oprimidas, conscientizar-se da disputa em questão, desenvolver a sua capacidade de expressão e lutar pelo seu direito de exprimir-se, de falar a sua palavra e de mudar a sua realidade. $\mathrm{Na}$ concepção de Freire (1987): 
Não há palavra verdadeira que não seja práxis. Daí que dizer a palavra verdadeira seja transformar o mundo. (...) Existir humanamente é pronunciar o mundo, é modifica-lo. (...) Não é no silêncio que os homens se fazem, mas na palavra, no trabalho, na ação-reflexão. Mas, se dizer a palavra verdadeira, que é trabalho, que é práxis, é transformar o mundo, dizer a palavra não é privilégio de alguns homens, mas direito de todos (FREIRE, 1987, p. 77-78).

Precisamente por ser um direito de todos, a palavra não pode ser pronunciada sozinha, por apenas uma pessoa ou uma classe social. É indispensável que haja diálogo. Freire, porém, nos alerta que não há diálogo se não houver um profundo amor ao mundo e aos homens.

Aderente à base teórica acima apresentada, na seção seguinte será discutida a proposta metodológica de alfabetização colocada em prática, há mais de 30 anos, pelo Cedep e UnB nas comunidades do Paranoá e Itapoã.

\section{eixos da Alfabetização de JOVens e adultos No PARANOÁ E ITAPOÃ}

Partindo do princípio, proposto por Vigotski (2009), de que o sujeito se constitui no conjunto das relações sociais, que são próprias e específicas de cada modo de produção, vigente em cada época, verificamos que o sujeito se constitui a partir do outro. Nesse sentido, Reis (2000) destaca que:

Não basta aprender a falar, pensar. É preciso aprender a ouvir/escutar elaborando o que o outro sujeito falante está dizendo, e ao dizer o que está pensando. Isso pressupõe um sentimento de ser acolhido pelo outro e de acolher o outro. Ouvir/escutar o outro, elaborando em cima do que fala, e responder sobre o que falou e naturalmente pensou. Da mesma forma, o outro, até então falante, passa a ouvir/escutar elaborando o que o outro está dizendo. E nessa alternância de sujeitos falantes/pensantes/atuantes e ouvintes/escutantes/elaborativos, o sujeito e os sujeitos estão se constituindo, tendo como chão a materialidade de suas condições históricas de vida (REIS, 2000, p. 4).

Essa predisposição à escuta sensivel e elaborante, que valoriza o outro, é o primeiro passo para a constituição de sujeitos amorosos, capazes de, nas suas relações com colegas e amigos, dentro e fora da sala de aula, contribuírem para a construção de um ambiente dialógico de aprendizagem, no qual impere a permanente disposição de acolher o outro e ser acolhido. 
O ambiente dialógico de aprendizagem, na medida em que contribui para que o aluno desvele os véus da hegemonia dominante que o leva pensar o mundo a partir da palavra alheia, contribui para a formação de sujeitos epistemológicos, construtores de saber, que descobrem-se seres políticos, de poder, capazes de mudar a realidade na qual estão inseridos.

Esse ato de transformação e empoderamento viabiliza aos sujeitos a produção e o acesso a novos conhecimentos, num ciclo contínuo de retroalimentação da equação saber-poder-saber. Dessa forma, saber e poder estão implicados numa relação dialética: saber como forma de poder, poder como forma de saber, uma vez que:

Quando o sujeito adquire e produz saber (sujeito epistemológico), ele adquire poder. E ao exercer poder, ele também adquire e produz saber. Produzir saber é produzir poder. E ao exercer poder, se produz e adquire saber. Poder e saber radicados em uma sociedade concreta. E concreta no caso brasileiro, tem a marca do modo de produção capitalista, produtor da exclusão do excluído (REIS, 2000, p. 44).

Metodologicamente, a práxis intrínseca a esses principios está ancorada em quatro eixos principais: acolhimento, fórum, situaçãoproblema-desafio e texto coletivo. O processo se inicia pela formação das turmas, com cada educador iniciando uma busca ativa por potenciais alunos da região.

Essa busca é realizada com muita amorosidade, procurando sensibilizar o potencial educando do seu direito e da sua capacidade em retomar os estudos. Esse ato representa o início do processo de acolhimento, que tem continuidade em sala de aula, quando a turma já está plenamente formada.

Conforme atestam Vieira, Reis e Sobral (2015), esse momento é de suma importância uma vez que os alunos são seres silenciados e em silenciamento. O silêncio e o encolhimento são as marcas dessas pessoas, que precisam de um clima de aconchego e confiança para que possam iniciar seu processo de dissilenciamento. 
Isso implica uma abertura ao outro e a coragem de falarem de si, dos seus problemas, história e origem, com a certeza de que não serão humilhados ou rejeitados pelo grupo. Nesse ambiente acolhedor, que deve imperar ao longo de todo o curso, o educando torna-se mais forte e consciente da sua capacidade de produzir conhecimento.

Após a semana inicial de acolhida e convivência mútua, as turmas participam do fórum, uma reunião geral coletiva, que reúne todos os educandos e educadores que participam das diversas turmas de alfabetização em andamento na comunidade.

Nesse encontro, são identificadas as situações-problemas-desafios por eles enfrentadas que, segundo Reis (2000, p. 47) dizem respeito “às necessidades econômicas, financeiras, sociais e culturais que caracterizam o quotidiano vivido/enfrentado pelos moradores do Paranoá, como decorrência da lógica excludente inerente à distribuição da riqueza econômica e cultural produzida no país".

Uma vez debatidas, são escolhidas democraticamente, a partir de votação, as mais urgentes, ou seja, aquelas que representam um maior obstáculo à dignidade e bem-estar da população, que se tornarão o eixo dorsal do processo alfabetizador.

Ao longo do processo de alfabetização, as possiveis alternativas de superação das situações-problemas-desafios priorizadas são analisadas por cada turma em rodas de conversa, procurando-se abordar, de forma interdisciplinar, as diversas questões subjacentes e inter-relacionadas. Ao final de cada aula, é produzido um texto coletivo pelos alunos, construído a partir da transformação da palavra falada em palavra escrita, por meio do registro do diálogo travado em sala.

Dessa forma, conforme atestam Vieira, Reis e Sobral (2015), não se adotam livros didáticos, mas sim textos coletivos. A partir das suas sentenças, frases e palavras, são trabalhadas a leitura e a escrita. É importante perceber que as palavras estudadas estão conectadas com a realidade dos alunos. Elas não são aleatórias. Ao fazer a leitura das palavras, o alfabetizando faz, na verdade, a leitura do mundo que o cerca, 
como agente ativo, capaz de engendrar mudanças em si, nos outros e na comunidade. Entretanto, para que a metodologia proposta seja implementada de forma satisfatória, é indispensável uma boa formação dos alfabetizadores.

Nesse sentido, antes de iniciarem a busca ativa por alunos para formação das suas turmas, os alfabetizadores realizam um curso de formação inicial, de 40hs, concebido a partir da metodologia acima apresentada, no intuito de lhes fornecer subsídios concretos para atuação em sala de aula.

$\mathrm{Na}$ seção seguinte, abordaremos mais detalhadamente a práxis adotada em 2016 na formação dos educadores do Programa DF Alfabetizado, lócus da pesquisa em referência e foco do presente artigo.

\section{PRÁXIS ADOTADA NA CAPACITAÇÃO INICIAL DOS EDUCADORES DO DF ALFABETIZADO QUE PARTICIPARAM DO $4^{\circ}$ CURSO DE FORMAÇÃO}

As regiões administrativas do Paranoá e do Itapoã vão muito além do seu perímetro urbano, possuindo uma extensa área rural, de grande expressividade, formada por propriedades de micro e pequenos produtores organizados em Associações e Cooperativas Agrícolas.

Nesse sentido, o $4^{\circ}$ Curso de Formação Inicial de Educadores do DF Alfabetizado, realizado em 2016, foi desdobrado em dois eventos. O primeiro, voltado aos 27 educadores que atuam na área urbana, foi realizado de 07 a 18 de março de 2016, no Cedep, com carga horária de 4hs/dia, ao longo de 10 encontros. O segundo, voltado aos 10 educadores que atuam na área rural, ocorreu aos sábados, no período de 09 de abril a 14 de maio, na escola classe da colônia rural do Café sem Troco, pertencente à área rural do Paranoá, com carga horária de $8 \mathrm{hs} /$ dia, ao longo de cinco encontros. Os princípios teóricos e a metodologia adotada em ambos os eventos foram os mesmos, porém a dinâmica de aplicação foi diferenciada, em função do número de alfabetizadores em cada turma e da carga horária diária dos cursos. 
Metodologicamente, o curso buscou conjugar prática e teoria, por meio de oficinas vivenciais, passiveis de serem ressignificadas pelos educadores em conjunto com os seus alfabetizandos, considerando-se a realidade de cada turma. As oficinas vivenciadas no curso em referência, que têm como principal característica o amplo debate entre os participantes, versaram sobre os seguintes temas:

a) Amorosidade no acolhimento dos alunos;

b) Identificação das situações-problemas-desafio da comunidade e encaminhamento de alternativas para sua superação;

c) Construção de textos coletivos em sala de aula;

d) História de vida dos participantes;

e) Mobilização dos movimentos populares pela fixação dos moradores;

f) Uso cotidiano da matemática;

g) Avaliações diagnósticas;

h) Uso de novas tecnologias em sala de aula;

i) Planejamento escolar e a construção de planos de aula.

Dessa forma, ao longo do curso, os educadores foram acolhidos de forma amorosa, ou seja, foram respeitados na sua diversidade, escutados e compreendidos nos seus desejos, anseios e necessidades. Segundo Reis, Vieira e Sobral (2015) o trabalho do Genpex é realizado com pessoas excluídas da sociedade. Essa exclusão é afetivo-amorosa, econômica, politica, cultural, epistemológica e familiar. São pessoas silenciadas e em silenciamento, com uma autossignificação de que "nada sou", "nada sei", "nada posso", "não tenho força”, "sou um zero a esquerda”, "analfabeto nada é”, “não tenho nenhum valor", "ninguém gosta de mim”.

Ao serem acolhidos e reconhecidos em sua especificidade, passam a construir uma visão diferente de si e do outro. Buscou-se durante o processo de formação que os educadores experimentassem o acolhimento que devem proporcionar aos seus alunos. Neste sentido, simularam o fórum inicial para priorização das situações-problemas-desafios da comunidade, bem como as rodas de conversa subsequentes para discussão das suas alternativas de superação e elaboração de textos coletivos. 
Paralelamente, exercitaram a escuta sensível em relação à história de vida dos seus pares, apoiando-se na empatia para perceber o universo afetivo, imaginário e cognitivo do outro (BARBIER, 2002), e discutiram as principais lutas e conquistas do movimento social forjadas em sua comunidade, fortalecendo, a cada oficina realizada, a sintonia entre a turma e viabilizando a criação de uma identidade de grupo. A partir dessas discussões foram produzidos textos coletivos, cujo intuito foi valorizar a voz dos educandos, trabalhar a partir de questões propostas por eles mesmos e que dizem respeito a sua realidade e encaminhar soluções aos problemas vividos na comunidade.

De acordo com Menezes (2013, p.12) "a construção do texto coletivo inicia-se no momento em que alfabetizandos e alfabetizadores, num diálogo tecido com base na escolha da situação-problema-desafio se expressam e discutem as dificuldades vivenciadas no dia-a-dia”. A partir dos registros oriundos da oralidade foram produzidos textos que se transformaram em atividades, as quais envolviam a lingua portuguesa, história, geografia e outros conteúdos.

Nesse contexto, vivenciaram também atividades relacionadas à matemática do cotidiano, que parte do principio de que, mesmo sem dominar os conceitos teóricos que a embasam, os educandos da EJA sabem efetuar cálculos envolvendo a compra de produtos no supermercado, o pagamento da passagem de ônibus, a noção de tempo cronológico e distância entre objetos e lugares.

Dessa forma, a partir de exercícios propostos, constataram que um mesmo problema pode ter mais de uma estratégia de solução. Verificaram, então, a importância do alfabetizador procurar compreender as hipóteses matemáticas que norteiam a aprendizagem dos seus alunos. Extrapolando esse princípio para a lingua portuguesa, verificaram que, de igual forma, a compreensão das hipóteses que norteiam o processo de aprendizagem da leitura e da escrita constitui-se em importante subsídio que poderá auxiliálos ao longo da alfabetização dos seus educandos. 
Além disso, vivenciaram oficinas de utilização do computador como uma nova linguagem, cujo foco não é aprender a manusear softwares, mas sim utilizar o micro como um novo suporte para a leitura e a escrita, em substituição ao papel. Assim, a depender da infraestrutura do local onde as suas turmas de alfabetização funcionarão, essa prática é também passível de ser por eles replicada junto aos seus alunos.

Por fim, os educadores experienciaram, de forma mais sistematizada, o processo de discussão e elaboração dos planos de aula, que apesar da sua extrema flexibilidade e adequação à realidade dos alunos, devem ser planejados a fim de que as aulas sejam produtivas e, acima de tudo, significativas e coerentes à realidade dos educandos. Segundo Tardif (2002), o professor é alguém que deve conhecer sua matéria, sua disciplina e seu programa, além de possuir certos conhecimentos relativos às ciências da educação e à pedagogia, de modo a desenvolver um saber prático baseado em sua experiência cotidiana com os alunos. Segundo este autor, o professor produz saberes por meio dos quais busca compreender ou dominar sua prática, denominados saberes práticos ou experienciais. Tais saberes fornecem aos educadores certezas relativas ao seu contexto de trabalho de modo a facilitar sua integração na prática docente.

Quanto à formação acadêmica e a experiência pedagógica dos educadores que atuam da área urbana verificou-se, a partir da apresentação realizada no primeiro dia do evento, que 21 dos 27 participantes, ou seja, $78 \%$ deles, já haviam concluído ou estavam em processo de conclusão de curso superior em pedagogia (14), letras (2), história (2), biologia (1), administração (1) ou gestão de recursos humanos (1). Em contrapartida, estavam, em sua maioria, atuando pela primeira vez no DF Alfabetizado.

Já dentre os demais, que possuíam apenas o ensino médio, a maioria estava na sua terceira ou quarta atuação no programa, o que tornou visivel a complementariedade do grupo: aqueles com nivel superior e, portanto, com maior bagagem teórica, estavam, em sua maioria, iniciando a prática alfabetizadora junto ao Programa, enquanto a maior parte daqueles sem formação universitária já possuía vasta experiência prática. Esse aspecto 
dicotômico viabilizou uma intensa e produtiva troca de conhecimento entre os alfabetizadores ao longo do curso, conforme pode ser observado a partir da análise da Tabela 1 a seguir:

\section{Tabela 1 - $4^{\circ}$ Curso de Formação Inicial de Educadores do DF Alfabetizado com atuação na área urbana do Paranoá e Itapoã - 2016 Formação acadêmica e experiência dos educadores}

\begin{tabular}{|c|c|c|c|c|c|c|c|c|c|c|}
\hline \multirow{2}{*}{$\mathbf{N}^{0}$} & \multirow{2}{*}{ Nome } & \multirow{2}{*}{ Região } & \multicolumn{4}{|c|}{ Formação } & \multicolumn{4}{|c|}{$\begin{array}{c}\text { Experiência } \\
\text { DF Alfabetizado }\end{array}$} \\
\hline & & & $\begin{array}{l}\text { Superior } \\
\text { completo }\end{array}$ & $\begin{array}{l}\text { Superior } \\
\text { incompleto }\end{array}$ & $\begin{array}{c}\text { Médio } \\
\text { Magistério }\end{array}$ & Médio & 1 & 2 & 3 & 4 \\
\hline 1 & Ana & Itapoã & & Pedagogia & & & $\operatorname{Sim}$ & & & \\
\hline 2 & Angélica & Paranoá & Gestão de RH & & & & $\operatorname{Sim}$ & & & \\
\hline 3 & Antônia & Paranoá & História & & & & $\operatorname{Sim}$ & & & \\
\hline 4 & Claudete & Paranoá & & Pedagogia & & & & & & Sim \\
\hline 5 & Cláudia & Paranoá Parque & Pedagogia & & & & Sim & & & \\
\hline 6 & Denilson & Paranoá & & Biologia & & & $\operatorname{Sim}$ & & & \\
\hline 7 & Dione & Paranoá & Pedagogia & & & & & & & Sim \\
\hline 8 & Dolores & Paranoá & & & Sim & & & & & Sim \\
\hline 9 & Eduardo & Paranoá & Pedagogia & & & & $\operatorname{Sim}$ & & & \\
\hline 10 & Eliene & Itapoã & Pedagogia & & & & & & & Sim \\
\hline 11 & Eva & Paranoá & Pedagogia & & & & & & & $\operatorname{Sim}$ \\
\hline 12 & Gleide & Paranoá & Pedagogia & & & & & & & $\operatorname{Sim}$ \\
\hline 13 & Jorge & Paranoá & Pedagogia & & & & $\operatorname{Sim}$ & & & \\
\hline 14 & José & Paranoá & Letras & & & & $\operatorname{Sim}$ & & & \\
\hline 15 & Joselice & Paranoá & Pedagogia & & & & & & & Sim \\
\hline 16 & Josilda & Itapoã & & & Sim & & Sim & & & \\
\hline 17 & Lindsey & Paranoá & & & & $\begin{array}{l}\text { Técnico em } \\
\text { Agropecuária }\end{array}$ & Sim & & & \\
\hline 18 & Lucineide & Paranoá & Pedagogia & & & & & & & Sim \\
\hline 19 & Maria & Paranoá & & & Sim & & & & & Sim \\
\hline 20 & Marina & Paranoá & & Pedagogia & & & Sim & & & \\
\hline 21 & Marisa & Paranoá & & & & $\begin{array}{l}\text { Técnico em } \\
\text { Edificações }\end{array}$ & & & $\operatorname{Sim}$ & \\
\hline 22 & Rosa & Itapoã & & & $\operatorname{Sim}$ & & & & $\operatorname{Sim}$ & \\
\hline 23 & Rosângela & Paranoá & & Administração & & & Sim & & & \\
\hline 24 & Sandra & Paranoá & Pedagogia & & & & $\operatorname{Sim}$ & & & \\
\hline 25 & Vera & Paranoá & Pedagogia & & & & $\operatorname{Sim}$ & & & \\
\hline 26 & \begin{tabular}{|l|} 
Vilma \\
\end{tabular} & Paranoá Parque & \begin{tabular}{|l} 
História \\
\end{tabular} & & & & & & & Sim \\
\hline 27 & Wellington & Itapoã & Letras & & & & $\operatorname{Sim}$ & & & \\
\hline
\end{tabular}

Fonte: Acervo das pesquisadoras 
Quanto ao perfil destes educadores ${ }^{3}$, delineado a partir da escuta sensível da história de vida da turma, tornou-se patente que todos têm em comum uma infância muito pobre, repleta de percalços e dificuldades, notadamente no que se refere à necessidade de conciliar trabalho e estudo para ajudar no sustento da família e da constante luta para não parar de frequentar a escola.

Histórias vividas, histórias repartidas. De intelectuais orgânicos, na melhor acepção gramsciniana do termo, muitos dos quais se formaram na EJA, galgaram o ensino superior e voltaram como educadores desta mesma EJA para caminhar lado a lado com seus semelhantes. Alguns, inclusive, são professores da rede regular de ensino da Secretaria de Educação.

É o caso de Eduardo que, como os demais, teve uma infância difícil. Estudou apenas até o $5^{\circ}$ ano. As 28 anos de idade, incentivado por colegas do clube onde trabalhava, concluiu o ensino médio na EJA e na sequencia estudou e se formou em Pedagogia. Desde 2013 é professor concursado da SEEDF e dá aulas para crianças na Escola Classe 03 do Paranoá.

É o caso também de Rosângela, que retomou o ensino médio na EJA para ajudar os filhos na escola, pois queria muito que eles não tivessem que interromper os estudos como ela. Depois, não parou mais: fez curso de auxiliar e, na sequência, de técnico em enfermagem, e trabalhou em hospitais. Iniciou o curso de administração, mas parou por motivos de saúde.

Sua filha Lindsay é a prova de que tamanho empenho deu certo: fez curso profissionalizante de técnico em agropecuária no Instituto Federal de Brasilia, onde atualmente trabalha como educadora e, juntamente com a sua mãe, está determinada em auxiliar no processo de emancipação das pessoas da sua comunidade.

Histórias de educadores, marcadas por lutas e enfrentamentos, semelhantes às histórias dos educandos da EJA. Muitas outras histórias poderiam ser contadas, no entanto o espaço disponível não permite este aprofundamento, uma vez que este texto buscou, de forma preliminar,

${ }^{3}$ Os nomes dos educadores citados neste artigo são fictícios 
discutir a historicidade e os fundamentos teórico-metodológicos da proposta formativa da parceria Universidade de Brasilia, Movimento Popular do Paranoá e Itapoã e Coordenação Regional de Ensino.

\section{CONSIDERAÇÕES FINAIS}

Este artigo não pretende esgotar a discussão sobre a formação de educadores populares, mas buscou trazer uma singela contribuição ao discutir aspectos relativos ao $4^{\circ}$ Curso de Formação Inicial de Educadores do DF Alfabetizado do Paranoá e Itapoã, realizado em 2016, que teve como pressupostos teóricos o materialismo histórico-dialético de Marx e Engels, a abordagem histórico-cultural de Vigotski e Bakhtin, a pedagogia libertadora de Freire e a proposta pedagógica de análise e superação de situaçõesproblemas-desafios, construção de textos coletivos, fórum e acolhimento dos alfabetizandos, conforme proposto por Reis.

Houve uma avaliação positiva do processo de formação vivenciado. Os educadores ressaltaram a importância das oficinas e o compromisso em adotá-las em suas turmas de alfabetização, com as adaptações pertinentes. Destacaram também o fato de serem oriundos da mesma comunidade dos seus educandos e, não obstante possuírem histórias de vida únicas e diferenciadas, compartilham um mesmo contexto socioeconômico e cultural, o que favorece o estabelecimento de empatia com os seus alfabetizandos, não obstante a singularidade de cada um deles.

Eles ressaltaram, entretanto, que apenas a formação inicial, de 40hs, não é suficiente para dar suporte à magnitude do trabalho a ser desenvolvido com as turmas de alfabetização. Dessa forma, solicitaram que após o início das aulas fosse realizado curso de formação continuada visando à troca de experiência entre os educadores, a discussão dos problemas enfrentados ao longo da prática educativa e o desenvolvimento conjunto de propostas visando a sua superação. 
Por fim, fica patente que os educadores possuem amplo conhecimento vivencial para organizarem as oficinas juntamente com os alfabetizandos, que são os protagonistas do seu processo de aprendizagem. Essa é, em última análise, a essência da proposta de alfabetização do curso de formação em questão, uma vez que o ser humano é um potencial produtor de conhecimento e deve exercer o seu direito de leitura e escrita do mundo. Não pode, portanto, permitir que outros exerçam esse poder por ele, nem tão pouco "depositem" unilateralmente informações descontextualizadas em suas mentes pois, conforme atesta Freire (1987, p. 69): "ninguém educa ninguém, como tampouco ninguém educa a si mesmo: os homens se educam em comunhão, mediatizados pelo mundo”.

\section{REFERÊNCIAS}

BAKHTIN, Mikhail. Marxismo e filosofia da linguagem: problemas fundamentais do método sociológico da linguagem. São Paulo (SP): Hucitec, 2014.

BARBIER, René. Escuta sensivel na formação de profissionais de saúde. 2002. Disponivel em http://www.barbier-rd.nom.fr/ESCUTASENSIVEL.PDF. Acesso em 12.10.2018.

BRASIL. Ministério da Educação. Princípios, Diretrizes, Estratégias e Ações de Apoio ao Programa Brasil Alfabetizado: Elementos para a Formação de Coordenadores de Turmas e de Alfabetizadores. 2011a. Disponivel em: http:// portal.mec.gov.br/index.php?Option= com_docman\&view=download\&alias $=10022$-diretrizes-principios-pbasecadi\&category_slug =fevereiro-2012-pdf\&Itemid=30192. Acesso em 05.01.18.

.Ministério da Educação/Fundo Nacional de Desenvolvimento da Educação. 2011. Resolução CD/FNDE $n^{\circ} 32$, de $1^{\circ}$ de julho de 2011. $2011 \mathrm{~b}$.

FREIRE, Paulo. Pedagogia do Oprimido. Rio de Janeiro (RJ): Paz e Terra, 1987.

GDF. Decreto $n^{\circ} 11.208$, de 17 de agosto de 1988. 1988. Disponível em: http://www.tc.df.gov.br/SINJ / Norma/16518/Decreto_11208_17_08_1988.h tml. Acesso em 05.01.18. 
Lei 3.527, de 03 de janeiro de 2005. 2005. Disponivel em: http://www.sedhab.df.gov.br/images/estudos_territorias/dossie_ras /itapua /lei_3527_27062000.pdf. Acesso em 05.01.18.

GDF/CODEPLAN. Pesquisa Distrital por Amostra de Domicílios PDAD/Itapoã2015. 2016. Disponivel em: http: / / www.codeplan.df.gov.br/images /CODEPLAN/PDF/pesquisa_ socioeconomica/pdad/2016/PDAD_Itapoa.pdf. Acesso em 05.01.18.

JESUS, Leila. A repercussão da atuação de educadores/as populares do Cedep/UnB na escola pública do Paranoá-DF. Dissertação (Mestrado em Educação). Brasília (DF): Universidade de Brasília, Faculdade de Educação, 2007.

MARX, Karl. Para a critica da economia politica. São Paulo: Nova Cultural, 1996.

MARX, Karl; ENGELS, Friedrich. A Ideologia Alemã. São Paulo (SP): Expressão Popular, 2009.

MENEZES, Janaína. A construção/constituição do texto coletivo para o processo de dessilenciamento do alfabetizando do Paranoá e Itapoã. Trabalho de Conclusão de Curso (Graduação em Pedagogia). Brasília (DF): Universidade de Brasília, Faculdade de Educação, 2013.

REIS, Renato. A constituição do sujeito politico, epistemológico e amoroso na alfabetização de jovens e adultos. Tese (Doutorado em Educação). Campinas (SP): Universidade de Campinas, Faculdade de Educação, 2000.

- A constituição do ser humano: amor-poder-saber na educação/alfabetização de jovens e adultos. Campinas (SP): Autores Associados, 2011.

TARDIF, Maurice. Saberes docentes e formação profissional. Petropólis, RJ: Vozes, 5 Ed. 2002.

SANTOS, Crislanqueni. O curso de formação inicial do Centro de Cultura e Desenvolvimento do Paranoá (Cedep): Singularidades e significação na perspectiva das alfabetizadoras populares. Trabalho de Conclusão de Curso (Graduação em Pedagogia). Brasília (DF): Universidade de Brasília, Faculdade de Educação, 2011.

VIEIRA, Maria. Clarisse; REIS, Renato; SOBRAL, Julieta. Educação de Jovens e Adultos como ato de amor, poder e saber: os desafios do Genpex. Brasília (DF): Fundação Universidade de Brasília, Decanato de Ensino de Graduação, 2015. 
VIGOTSKI, Lev. A construção do pensamento e da linguagem. São Paulo (SP): Martins Fontes, 2009. 